\title{
Ventilatory function and personal breathing zone dust concentrations in Lancashire textile weavers
}

\author{
S N Raza, A M Fletcher, C A C Pickering, R McL Niven, E Faragher
}

\begin{abstract}
Background-To report findings on ventilatory function and estimations of concentrations of personal breathing zone dust in Lancashire textile weavers. Weaving room dust is considered to be less harmful than that encountered in the cardroom or spinning room and weavers are generally thought to have less respiratory disability than carders or spinners. However, this occupational group has not been extensively studied.
\end{abstract}

Methods-Each person was given a respiratory symptom questionnaire (modified Medical Research Council, UK, questionnaire on respiratory diseases). Ventilatory function tests, forced expiratory volume in 1 second $\left(\mathrm{FEV}_{1}\right)$ and forced vital capacity (FVC) were performed on each person. A representative sample of workers from each occupational group underwent dust sampling in their personal breathing zone. Dust concentrations and ventilatory tests were analysed statistically with the Student's $t$ test, Pearson's correlation coefficient, and forward step regression for relations with symptoms and environmental factors. Significance was $p \geqslant 0.05$. Results-The FEV 1 and FVC were reduced in workers with respiratory symptoms (non-specific chest tightness, shortness of breath, persistent cough, and wheezing) as well as in preparation room workers, current and former smokers, Asians, those working with predominantly cotton fibre ( $>50 \%$ cotton) and starch size. Mean total dust concentration (pd1) in the personal breathing zone was $1.98 \mathrm{mg} / \mathrm{m}^{3}$. The corresponding value for total dust with large fibres lifted off the filter paper (pd2) was $1.55 \mathrm{mg} / \mathrm{m}^{3}$.There was a strong correlation $(r=0.94, p<0.0001)$ between pd1 and pd2. Non-specific chest tightness was predicted by low dust concentrations and persistent cough by high dust concentrations. On regression analysis, impairment of ventilatory function $\left(\mathrm{FEV}_{1}, \mathrm{FVC}\right)$ was predicted by smoking, male sex, age, not working in the weaving shed, not being white, and personal dust concentrations. Conclusions-The FEV $_{1}$ and FVC were impaired in smokers and those exposed to high dust concentrations in the personal breathing zone. Symptoms were inconsistently related to dust concentrations in the personal breathing zone.

(Occup Environ Med 1999;56:520-526)

Keywords: weavers; dust concentrations; personal sampling; spirometry; textiles
It has been recognised for a long time that dust in the textile environment is related to respiratory illness. ${ }^{1-3}$ Investigators at the turn of the century $^{45}$ and in the $1930 \mathrm{~s}^{6}$ documented the high prevalence of disease and disability among cotton operatives. Since then, important advances have been made in the epidemiology of disease associated with work in the cotton mills. Several investigators have shown respiratory disability in cotton workers, based on clinical and ventilatory function evaluation. ${ }^{7-19}$ There is some debate regarding the optimum ventilatory test for assessment of respiratory disability in textile workers. ${ }^{17}{ }^{20}{ }^{21}$ In the United Kingdom, the ventilatory test used most often is forced expiratory volume in 1 second $\left(\mathrm{FEV}_{1}\right)$

Until recently, area or workzone sampling was carried out and used for setting standards of occupational exposure. Several studies showed a good correlation between respiratory symptoms and dust concentrations..$^{11} 112223$ Cinkotai et $a l^{12}{ }^{13}$ used both workzone and personal breathing zone dust sampling. They found that personal breathing zone dust sampling correlated better with byssinotic symptoms. Recent work has also shown that in operatives exposed to cotton, up to 10 -fold variation in exposure to dust can occur when comparing these two methods. ${ }^{24}$ However, most of the work already referred to has been carried out on cotton spinners, and not on weavers. It has been suggested that dust in the weaving shed is different, as a large part of it consists of "size" (a coating of starch, or other material, applied to yarn before it is submitted for weaving), which is liberated during the weaving process. Application of a coating of size may also prevent cotton dust from being liberated during the weaving process. The thought that weaving room dust is less injurious for health is reflected in the dust standards recommended by Corn, for the United States ${ }^{25}$ - that is, a level of $0.75 \mathrm{mg} / \mathrm{m}^{3}$ for weaving and sizing and $0.20 \mathrm{mg} / \mathrm{m}^{3}$ for yarn manufacture and cotton washing. The generally held view is that byssinosis and other symptoms are not major problems for textile weaving. However, a few investigators have reported high prevalence of byssinosis and respiratory disability in cotton weavers. ${ }^{26-29}$

We used a respiratory symptom questionnaire, spirometry, and measurement of total inhalable dust in the personal breathing zone to study textile weavers around Manchester. Respiratory symptoms and factors associated with them are the subject of a separate paper. Ventilatory function and dust concentrations in the 
Table 1 Number of people sampled and total number of samples in each mill

\begin{tabular}{lrccc}
\hline Mill & $\begin{array}{l}\text { Total } \\
\text { seen }\end{array}$ & $\begin{array}{l}\text { People } \\
\text { sampled }(n)\end{array}$ & $\begin{array}{l}\text { People sampled } \\
\text { twice }(n)\end{array}$ & $\begin{array}{l}\text { Total samples } \\
(n)\end{array}$ \\
\hline 1 & 261 & 39 & 35 & 74 \\
2 & 144 & 23 & NIL & 23 \\
3 & 32 & 12 & 12 & 24 \\
4 & 99 & 21 & 19 & 40 \\
5 & 64 & 21 & 18 & 39 \\
6 & 29 & 13 & NIL & 13 \\
7 & 71 & 15 & NIL & 15 \\
8 & 34 & 11 & 11 & 22 \\
9 & 30 & 16 & 10 & 26 \\
10 & 93 & 20 & NIL & 20 \\
11 & 50 & 12 & 12 & 24 \\
12 & 79 & 19 & NIL & 19 \\
13 & 19 & 11 & NIL & 11 \\
14 & 19 & 8 & NIL & 8 \\
15 & 39 & 20 & 20 & 40 \\
16 & 232 & 41 & 32 & 73 \\
Total & 1295 & 302 & 169 & 471 \\
\end{tabular}

personal breathing zone and their relation to symptoms are presented in this paper.

\section{Methods}

The study was cross sectional in design and conducted in the Lancashire area. Sixteen mills were surveyed. We did not have previous knowledge of working conditions in these mills. Every worker participating in the study was given a modified Medical Research Council (MRC), UK, respiratory symptom questionnaire. It is based on the original MRC respiratory questionnaire ${ }^{30}$ with additional questions to identify byssinosis and other work related respiratory symptoms, and was validated for the study. If a symptom improved when away from work, it was said to be work related. Personal factors recorded were age, height, sex, and ethnic origin. Smoking data included questions to allow for a calculation of packyears for ex-smokers or current smokers and years since stopped smoking for current non-smokers. Grade of cotton being processed (coarse, medium, or fine), type of preparation processes, and size (starch or polyvinylalcohol) were recorded. The type of loom (shuttle, air jet, projectile, rapier, or water jet) and its speed (in picks per minute) were also documented. Occupational histories included duration of all current and past textile experience. Four workroom and six occupational groups were identified from over 50 different occupations. These identified groups large enough to be included in statistical analysis, and which had similar type and extent of exposure in each mill.

\section{LUNG FUNCTION TESTS}

Measurement of timed vital capacity has been extensively used in the assesment of textile workers. The $\mathrm{FEV}_{1}$ has good reproducibility, ${ }^{31}$ and is easily applied in a field setting. Changes in the maximal midexpiratory flow have been shown in cotton operatives by many workers. ${ }^{16} 1932$ It has been suggested that indices based on the maximum expiratory flow volume curve are better than $\mathrm{FEV}_{1}$, when studying ventilatory function of cotton workers, as the cotton dust reaction starts in peripheral airways. The reproducibility of forced expiratory flows, however, is only moderate. ${ }^{33}$ Hence we measured $\mathrm{FEV}_{1}$ and forced vital
Table 2 Mean (SD) dust concentrations in the mills $\left(\mathrm{mg} / \mathrm{m}^{3}\right)$

\begin{tabular}{llll}
\hline Mill & $\begin{array}{l}\text { Workers sampled } \\
(n)\end{array}$ & $\begin{array}{l}\text { Total dust } \\
\left(\mathrm{mg} / \mathrm{m}^{3}\right)\end{array}$ & $\begin{array}{l}\text { Total dust less fly } \\
\text { (manually } \\
\text { removed) }\left(\mathrm{mg} / \mathrm{m}^{3}\right)\end{array}$ \\
\hline 1 & 39 & $2.38(1.44)$ & $1.42(0.94)$ \\
2 & 23 & $2.60(1.96)$ & $2.27(2.0)$ \\
3 & 12 & $2.49(1.72)$ & $1.82(0.93)$ \\
4 & 21 & $2.24(1.13)$ & $1.98(0.93)$ \\
5 & 21 & $1.52(1.09)$ & $1.29(0.79)$ \\
6 & 13 & $1.10(0.52)$ & $1.04(0.50)$ \\
7 & 15 & $1.26(1.04)$ & $1.08(0.90)$ \\
8 & 11 & $1.03(0.29)$ & $0.73(0.20)$ \\
9 & 16 & $2.59(1.17)$ & $2.11(0.77)$ \\
10 & 20 & $0.62(0.57)$ & $0.58(0.55)$ \\
11 & 12 & $2.77(0.99)$ & $2.04(0.46)$ \\
12 & 19 & $2.28(1.23)$ & $1.94(1.10)$ \\
13 & 11 & $2.08(1.18)$ & $1.82(0.96)$ \\
14 & 8 & $6.67(3.32)$ & $5.48(2.95)$ \\
15 & 20 & $2.69(1.60)$ & $2.41(1.56)$ \\
16 & 41 & $1.24(0.62)$ & $1.00(0.62)$ \\
& & &
\end{tabular}

capacity (FVC) in our study population. Because of the size of the workforce studied, it was not possible to perform spirometry across the shift, or measure ventilatory function at the same time of the day or on the same day of the working week. Every attempt was made to measure ventilatory function in the early part of the shift. The same Vitalograph-S model spirometer was used throughout the study. Before a visit to a mill the spirometer was calibrated with a precision 11 syringe. Upon arrival in the mill, the instrument was left unused for 2 hours. A record of room temperature was kept. The forced expiratory manoeuvre was explained to the worker. Usually the subject required two or three practice measurements while any errors were corrected. The operative was encouraged to exhale for as long as he or she could. A nose clip was used only if the technique was unsatisfactory. Care was taken to avoid the Valsalva manoeuvre, obstruction by tongue, cough, or early termination. The acceptability of the manoeuvre was determined by satisfactory start and end of test criteria and a minimum exhalation time of 6 seconds. Three forced expiratory manoeuvres within $5 \%$ of each other were obtained in the standing position. The greatest values for $\mathrm{FEV}_{1}$ and FVC were read off the scale at atmospheric temperature and pressure at saturation (ATPS), regardless of whether or not they occurred on the same curve. These values were later corrected for temperature.

For white workers, predicted spirometric values were derived from the summary equation of reference values. ${ }^{34}$ To calculate predicted lung function variables for Asians, correction factors were used as suggested by Cotes $^{35}$ - that is, for Asian men 0.71 and 0.451 were subtracted from the predicted FVC and $\mathrm{FEV}_{1}$ of age and height matched white men; for Asian women the corresponding figures were 0.61 and 0.41 . The variables $\left(\mathrm{FEV}_{1}, \mathrm{FVC}\right)$ were then stored as the percentage of predicted values.

DUST SAMPLING

Personal breathing zone dust was measured with the sampler developed by the Institute of Occupational Medicine, Edinburgh (IOM). ${ }^{36}$ Its performance is close to inspirability over a 
Table 3 Mean (SD) dust concentrations by present workroom and occupation

\begin{tabular}{lll}
\hline & $\begin{array}{l}\text { Total dust } \\
\left(\mathrm{mg} / \mathrm{m}^{3}\right)\end{array}$ & $\begin{array}{l}\text { Total dust less fly } \\
(\text { manually removed }) \\
\left(\mathrm{mg} / \mathrm{m}^{3}\right)\end{array}$ \\
\hline $\begin{array}{l}\text { Occupation: } \\
\text { Weaving I }\end{array}$ & $1.82(1.00)$ & $1.46(0.78)$ \\
Weaving II & $1.91(1.63)$ & $1.79(1.54)$ \\
Cloth inspection & $1.74(1.95)$ & $1.37(1.43)$ \\
Weaving III & $1.96(1.59)$ & $1.64(1.26)$ \\
Preparation & $1.69(1.60)$ & $1.23(1.33)$ \\
Sewing room & $2.58(1.75)$ & $1.79(1.59)$ \\
Workroom: & $1.86(1.33)$ & $1.57(1.12)$ \\
$\quad$ Weaving & $1.75(1.60)$ & $1.27(1.35)$ \\
Preparation & $2.52(1.67)$ & $1.78(1.59)$ \\
Sewing & $1.90(2.12)$ & $1.38(1.42)$ \\
Cloth inspection & \multicolumn{2}{l}{} \\
Weaving I=those working directly on looms; weaving \\
II=those in the proximal vicinity of looms; weaving \\
III=those exposed to high dust levels while employed in the \\
weaving shed.
\end{tabular}

wide range of particle size and wind speed. Whatman GF/A microglass fibre filters were mounted in the cassettes inside the sampling head. The cassettes were weighed before the sampling exercise on a single pan microbalance (Sartorius) having a verified precision better than $\pm 0.01 \mathrm{mg} .{ }^{37}$ The sampling heads were then transported to the mill. In the mill, the sampling heads were pinned onto the lapels of operatives, secured safely, and connected to Casella pumps (worn on the waist) for the duration of the shift. Flow rate $(2 \mathrm{l} / \mathrm{min})$ was checked periodically with a flow meter. Pumps were switched off during breaks. Time of active sampler use was carefully recorded. On return from the mill, the cassettes inside the sampling heads were reweighed to obtain the weight change. A few sampling heads (blanks) were not opened in the mill, but treated like the active sampling heads for weighing before and after the visit. Mean change in the weight of blanks was called the correction factor. If positive, it was subtracted from (if the correction factor was negative, it was added to) the weight change of cassettes used for sampling to obtain the corrected weight change. The level thus measured was termed total inhalable dust in the personal breathing zone of the operative (pd1). In a study by Cinkotai et $a l^{13}$ good correlation was reported between symptoms and dust concentrations in the personal breathing zone (measured by a sampling head with a 2 $\mathrm{mm}$ wire gauze mesh mounted on it to exclude larger particles or fly). The IOM sampler does not have wire mesh mounted on it. Hence, another dust fraction called "total dust less fly" $(\mathrm{pd} 2)$ was measured. After weighing after the visit, to calculate pd1 the "fluff" or "fly" was

Table 4 Factors associated with high dust concentrations (univariate analysis)

\begin{tabular}{lll}
\hline Factor & t Value & $p$ Value \\
\hline Total dust: & -7.5 & \\
Cotton rather than man made fibre & ANOVA & 0.001 \\
Work in sewing room & ANOVA & 0.05 \\
Work with medium cotton grade & ANOVA & 0.05 \\
Work with starch size & ANOVA & 0.05 \\
$\quad$ Work with looms other than waterjet looms & & \\
Total dust with fly manually removed: & -4.3 & 0.001 \\
Cotton rather than man made fibre & ANOVA & 0.05 \\
Work in sewing room & ANOVA & 0.05 \\
Work wth medium cotton grade & ANOVA & 0.05 \\
Work with starch size & ANOVA & 0.05 \\
Work with looms other than waterjet looms & & \\
\hline
\end{tabular}

Table 5 Work related symptoms associated with high dust concentrations (univariate analysis)

\begin{tabular}{lrl}
\hline Factor & $t$ Value & $p$ Value \\
\hline Total dust (pd1): & & \\
$\quad$ Persistent cough & 2.36 & 0.019 \\
Total dust less fly (pd2): & & \\
$\quad$ Ocular symptoms & -1.99 & 0.05 \\
Persistent cough & 2.24 & 0.025 \\
\hline
\end{tabular}

Table 6 Mean (SD) values of ventilatory function for each mill

\begin{tabular}{llr}
\hline Mill & FEV $(\%$ predicted $)$ & FVC (\% predicted $)$ \\
\hline 1 & $86.43(25.67)$ & $86.28(24.48)$ \\
2 & $91.56(22.70)$ & $96.49(22.70)$ \\
3 & $97.01(13.74)$ & $101.17(10.16)$ \\
4 & $91.89(23.73)$ & $98.28(25.39)$ \\
5 & $99.25(17.15)$ & $104.84(15.40)$ \\
6 & $97.39(17.44)$ & $100.77(17.00)$ \\
7 & $94.79(20.62)$ & $99.78(21.56)$ \\
8 & $94.29(27.80)$ & $102.07(26.47)$ \\
9 & $91.48(21.60)$ & $98.16(16.79)$ \\
10 & $98.75(19.14)$ & $101.94(19.10)$ \\
11 & $97.07(14.54)$ & $101.78(13.31)$ \\
12 & $93.42(25.48)$ & $98.75(25.50)$ \\
13 & $90.89(19.46)$ & $101.39(17.89)$ \\
14 & $91.25(15.94)$ & $95.24(15.63)$ \\
15 & $89.45(26.83)$ & $96.53(27.28)$ \\
16 & $93.47(23.32)$ & $99.46(22.57)$ \\
\end{tabular}

picked off with a pair of forceps and the cassette reweighed. The $\mathrm{pd} 2$ was calculated from this reading of the weight after the visit. This method, although rather crude, was performed to determine whether pd2 correlated better with symptoms.

The aim of the dust sampling exercise was to sample $20 \%-25 \%$ of the workers across the occupational groups encountered. Within a group, the required number of workers were chosen randomly. If a worker refused, another one from the same occupational category was asked to participate in dust sampling. The aim was to sample each worker on two separate occasions. On the second visit, if the same worker was not available, another one performing the same task was requested to wear the sampling equipment. The mean dust concentrations ( $\mathrm{pd} 1$ and $\mathrm{pd} 2$ ) for each occupational group in a mill were obtained. This average value for each occupational group was ascribed to all members of the same occupation not undergoing sampling in the same mill. All occupations did not have the same number of workers, all occupations were not encountered in every mill, and all mills did not agree to two dust sampling visits. Hence, there was variation in the proportion of operatives sampled in each occupational group.

STATISTICAL ANALYSIS

Data about lung function tests and dust concentrations were first stored in a database (dbase III plus), along with information about personal factors, environmental factors, and symptoms. Further analysis was carried out with the SPSS and BMDP programmes. Factors most likely to be associated with each symptom, lung function, and dust concentrations were identified. Forward step multiple regression analysis was carried out to identify factors associated with impairment in $\mathrm{FEV}_{1}$ and FVC. When submitting variables for 
Table 7 Factors associated with reduced lung function (univariate analysis)

\begin{tabular}{lll}
\hline Factor & $t$ Value & $p$ Value \\
\hline FEV $_{1}$ \% predicted): & & \\
$\quad$ Present smoker & -2.33 & 0.02 \\
Cotton rather than man made fibre & -2.2 & 0.03 \\
Work in preparation room & ANOVA & 0.05 \\
Work with starch size & ANOVA & 0.05 \\
Asian ethnicity & 2.31 & 0.02 \\
Male sex & -1.24 & $\mathrm{NS}$ \\
FVC (\% predicted): & & \\
Cotton rather than man made fibre & -2.4 & 0.016 \\
Work in preparation room & ANOVA & 0.05 \\
Work with starch size & ANOVA & 0.05 \\
Medium grade cotton & AN OVA & 0.05 \\
Asian ethnicity & 2.2 & 0.03 \\
Male sex & -1.59 & $\mathrm{NS}$ \\
\hline
\end{tabular}

Table 8 Work related symptoms associated with reduced lung function (univariate analysis)

\begin{tabular}{lll}
\hline Factor & $t$ Value & $p$ Value \\
\hline FEV $_{1}$ (\% predicted): & & \\
$\quad$ Chronic phlegm production & -3.34 & 0.001 \\
Non-specific chest tightness & -2.66 & 0.01 \\
Nasal symptoms & 2.8 & 0.005 \\
Shortness of breath & -4.26 & $<0.0001$ \\
Persistent cough & -2.43 & 0.019 \\
Wheezing & -4.05 & $<0.0001$ \\
FVC (\% predicted): & & \\
Non-specific chest tightness & -2.09 & 0.04 \\
Nasal symptoms & 2.14 & 0.033 \\
Shortness of breath & -2.96 & 0.006 \\
Persistent cough & -2.38 & 0.021 \\
Wheezing & -3.35 & 0.001 \\
\hline
\end{tabular}

univariate and multivariate analyses, log normally distributed data were log transformed.

\section{Results}

Of the 1295 workers interviewed with a questionnaire, 302 participated in dust sampling. Seven mills (454 workers) did not agree to a second dust sampling exercise. Hence, only 169 of the 302 workers could be sampled twice. This gave a total of 471 dust samples (weaving shed 179, preparation 51, sewing room 35, cloth inspection 37). The number of workers sampled in each mill are given in table 1. The percentage of workers sampled in each workroom were: weaving $25.3 \%$, preparation $26.7 \%$, sewing $13.4 \%$, and cloth inspection $30.3 \%$. Table 2 lists the mean dust concentrations in each mill. Dust concentrations in the workrooms and occupations are shown in table 3. The highest dust concentrations were encountered in operatives of the sewing room. Dust concentrations in workers employed in the rest of the workrooms were very similar to each other. Factors associated with total inhalable dust (univariate analysis) are listed in table

Table 9 Independent predictors of reduced lung function (mulivariate analysis)

\begin{tabular}{llll}
\hline Factor & B value & SEM & p Value \\
\hline FEV $_{\mathrm{r}}$ : & $-8.3 \mathrm{E}-4$ & $1.30 \mathrm{E}-4$ & $<0.0001$ \\
Cumulative smoking & -8.3 & 1.90 & $<0.0001$ \\
Asian ethnicity & -0.2 & 0.04 & $<0.0001$ \\
Age & 4.9 & 1.09 & $<0.0001$ \\
Male & -3.3 & 1.07 & 0.0023 \\
Not working in the weaving shed & -1.4 & 0.70 & 0.0412 \\
Total dust (pd) & & & \\
FVC: & -8.1 & 1.81 & $<0.0001$ \\
Asian ethnicity & -0.2 & 0.05 & $<0.0001$ \\
Age & 5.96 & 1.05 & $<0.0001$ \\
Male & -5.3 & 1.05 & $<0.0001$ \\
Not working in the weaving shed & -1.6 & 0.68 & 0.0195 \\
Total dust (pd1) & & & \\
\hline
\end{tabular}

4. These factors are similar for $\mathrm{pd} 1$ and $\mathrm{pd} 2$. Significantly higher dust concentrations were generated when cotton rather than man made fibre was being used, medium grade cotton was being woven, and when starch size was used. The lowest concentrations of dust were generated by water jet looms (mean pd $10.27 \mathrm{mg} / \mathrm{m}^{3}$, pd2 $0.23 \mathrm{mg} / \mathrm{m}^{3}$ ). Next dusty were air jet looms (mean pd1 $1.49 \mathrm{mg} / \mathrm{m}^{3}$, pd2 $1.13 \mathrm{mg} / \mathrm{m}^{3}$ ). They were significantly less dusty than the other loom types. The two dust fractions correlated well with each other $(r=0.94$, $\mathrm{p}<0.0001)$. No respiratory symptoms except work related persistent cough were associated with high concentrations of dust (pd1, pd1). Work related ocular symptoms were associated with lower concentrations of dust (table 5).

Altogether, 1295 operatives completed the questionnaire, and 33 were unable to comply with American Thoracic Society guidelines. ${ }^{38}$ Hence ventilatory function test results of 1262 workers are presented. Mean values by mill are listed in table 6 . Univariate analysis of factors associated with reduced lung function are given in table 7 . Both $\mathrm{FEV}_{1}$ and $\mathrm{FVC}$ were significantly reduced in smokers, those handling predominantly cotton rather than man made fibre, starch size, and employees in the preparation room. Percentage predicted $\mathrm{FEV}_{1}$ and FVC were lower in Asians than their white counterparts. The presence of work related chest symptoms was associated with reduced $\mathrm{FEV}_{1}$ and FVC (table 8). For work related nasal symptoms, this was not the case. On multiple regression analysis (table 9), cumulative smoking emerged as the strongest predictor of a reduced $\mathrm{FEV}_{1}$. Other factors predicting a reduction of this variable were greater age, male sex, and Asian ethnicity. Higher concentrations of total dust in the personal breathing zone predicted reduced $\mathrm{FEV}_{1}$. A low $\mathrm{FEV}_{1}$ was also associated with employment in workrooms other than weaving. Smoking habit was not an independent predictor of reduced FVC. Other predictors for this variable were similar to those for $\mathrm{FEV}_{1}$.

\section{Discussion}

\section{LUNG FUNCTION}

A large body of data suggests that cotton operatives are susceptible to acute ${ }^{839}$ and chronic respiratory disability. ${ }^{74}{ }^{40}$ An accelerated decline in lung function is also found in asymptomatic cotton workers ${ }^{11}{ }^{17}$ and in excotton workers. ${ }^{41}$ However, there is a paucity of lung function data for weavers. Because of the study design, changes in ventilatory function across the shift could not be assessed in our study. However, measurements were predominantly made at the beginning of the shift to minimise variation across the shift in the results.

White workers had higher values of $\mathrm{FEV}_{1}$ and FVC compared with Asians. Ethnicity emerged as an independent factor on carrying out regression for $\mathrm{FEV}_{1}$ and FVC. In their study of Lancashire spinners, however, Cinkotai et $a l^{13}$ and Fishwick et $a l^{18}$ described lower values of ventilatory function in the white workforce compared with Asians. They attrib- 
uted this to a shorter duration of exposure to the cotton industry in the case of Asians. However, these studies used a different correction factor for Asian people. The use of a correction factor to calculate predicted ventilatory function values in Asians was essential but may not be accurate. It has been suggested that predicted values for normal ventilatory function should ideally be computed from healthy members (unexposed) of the same community. This was not possible in this study as the number of Asians was small and all were exposed-that is, there were no controls. Local geographic and social factors influencing the Asian population may affect the suitability of a given correction factor. Thus, these findings cannot be accepted as indicating an increased susceptibility of Asians.

Male sex and increasing age emerged as significant independent predictors of reduced $\mathrm{FEV}_{1}$, despite standard correction attempted for both of them when calculating predicted values. The effect of age may also highlight the inadequacy of the predicted values currently in use, or may be an effect of cumulative occupational exposure.

The pattern of sex distribution across various occupations and workrooms is quite distinctive. Men usually carry out most of the work with high exposure to dust - such as loom maintainence, loom sweeping, etc. Also, with the exception of beaming and creeling, the preparation department is almost exclusively manned by men. Employees of this workroom had the lowest values for lung function. Interestingly, on regression analysis, not working in the weaving shed was associated with lower values of $\mathrm{FEV}_{1}$ and FVC. The preparation department is the next most dusty workroom after the spinning room.

Those exposed to starch size had significantly reduced $\mathrm{FEV}_{1}$ compared with polyvinyl alcohol size. The starch size consists of organic matter and may be more bioactive. However, size did not emerge as an independent factor on regression. Contrasting with the findings of Roach $^{22}$ and Mekky $^{9}$ we did not find exposure to a particular grade of cotton to be associated with reduced ventilatory function. Overall, those exposed to predominantly cotton fibre had significantly lower $\mathrm{FEV}_{1}(\mathrm{p}=0.027)$ and FVC $(p=0.016)$ compared with those exposed to fibres other than cotton. Accelerated loss of lung function has been shown in cotton operatives (compared with man made fibre operatives) by other research workers. ${ }^{14}$ In the present study (which documented predictors of $\mathrm{FEV}_{1}$, rather than a decline in $\mathrm{FEV}_{1}$ ), work with cotton (rather than man made fibre) did not emerge as an independent predictor for $\mathrm{FEV}_{1}$.

The relative contribution of smoking and employment in the textile industry in the cause of respiratory disability is a subject of much debate. It has been suggested that morbidity among textile workers is due to smoking. However, several investigators have established that the textile environment also causes disability and when smoking is present, the two are additive. ${ }^{174142}$ In the present study, smoking has, as expected, emerged as an independent predictor of reduced $\mathrm{FEV}_{1}$, but not FVC. However, equally important is the finding that two variables of the work environment (total inhalable dust and work not in the weaving shed) are also able to predict a reduced $\mathrm{FEV}_{1}$, independent of smoking. Equally interesting is the finding of a relation between total inhalable dust concentrations in the personal breathing zone and reduced FVC. The relation was stronger for FVC than $\mathrm{FEV}_{1}$. Such a relation has also been described for man made fibre. ${ }^{43}$ Most weaving units process a mixture of cotton and man made fibre. Whether the reduced values of FVC are due to cotton dust or reflect use of man made fibre, size, or some other factor in the environment of the weaving room cannot be concluded from available data.

\section{DUST CONCENTRATIONS}

Workers participating in the study tolerated the sampling exercise very well. Every attempt was made to carry out dust sampling on a representative sample of people from each occupation and workroom in the mills, so that results of dust sampling in a mill could be extrapolated to the workers of the same occupation or workroom in that mill. However, the potential for bias remains due to refusal of some workers to wear the sampling equipment and due to some workers being sampled once rather than twice.

The samplers measuring total inhalable dust (pd1) in the personal breathing zone of operatives did not have a wire mesh excluding larger particles. Previous studies had measured dust concentrations by prefiltering air through 2 $\mathrm{mm}$ wire mesh. Hence, another variable was derived, by manually lifting the fluff off the filter paper ( $\mathrm{pd} 2)$. However, manual removal of these large textile fibres confounds the issue, as it also leads to loss of finer dust trapped therein. Also, this technique depends on the observer, and therefore is less accurate. Mean (SD) pd1 concentration was 1.98 (1.55) $\mathrm{mg} / \mathrm{m}^{3}$. Mean (SD) $\mathrm{pd} 2$ concentration was $1.55(1.30) \mathrm{mg} / \mathrm{m}^{3}$. The correlation between the two dust fractions was good $(r=0.94$, $\mathrm{p}<0.0001$ ), but only pd 1 was a predictor of reduced $\mathrm{FEV}_{1}$ and FVC on regression analysis. Presumably, once pd 1 had emerged as an independent predictor of loss of ventilatory function, pd2 was rendered less beneficial.

Correlation between $\mathrm{FEV}_{1}$ and dust concentrations (time weighted, total dust less fly) was carried out by Fox et al. ${ }^{11}$ The correlation coefficient for non-smokers was -0.08 and for smokers -0.13 . Although we were dealing with a different population, and not measuring dust concentrations over time, we had very similar values of the correlation coefficient between dust concentrations and ventilatory function.

When cotton rather than man made fibre was being processed, pd1 and pd 2 concentrations were higher. Generally, coarse cotton produces the highest dust concentrations. ${ }^{13}$ However, we found that $\mathrm{pd} 1$ and $\mathrm{pd} 2$ concentrations were higher for medium rather than coarse cotton. The pd 1 and pd 2 produced with starch size were higher than those for polyvinyl 
alcohol or a combination of starch and polyvinyl alcohol size. This could, in part, explain the poor dose-response relation found for weaving sheds as most weaving room dust consists of size and not cotton dust. Also, the application of size reduces fragmentation and wear of the yarn, reducing the contribution of cotton fibres in weaving room dust. Studies showing a doseresponse relation between dust concentrations and symptoms ${ }^{13}$ have had to exclude the weaving workforce, as inclusion of it led to annulment of the dose-response relation (Cinkotai FF, personal communication). Quite predictably, although we found a relation between dust concentrations and loss of ventilatory function, we were unable to show a relation between symptoms and dust concentrations. This is contrary to findings of other studies $^{11} 1318$ in which such a relation was documented. However, these studies have been conducted on spinners or cardroom workers. The only symptom of the lower respiratory tract for which a dose-response relation was shown was persistent cough. However, even for this symptom, the strongest predictors were smoking $(p=0.0003)$, female sex $(p=0.0085)$, fine grade cotton $(\mathrm{p}=0.0268)$, then $\mathrm{pd} 2$ $(p=0.0246)$. Persistent cough is probably a heterogeneous symptom. Some cases could be forerunners of chronic bronchitis, and hence related to smoking. Other cases could be due to an irritant effect. Other irritant symptoms (ocular or eye irritation) are also more common in women. Workers exposed to fine grade cotton also complained of more ocular or nasal irritation.

Perhaps exposure to dust in weaving is sufficiently irritant that continued exposure over a long period can cause reduced ventilatory function. However, compared with cotton spinning, it is not sufficiently harmful to induce acute symptoms.

In conclusion, therefore, this large study of weavers shows that the highest dust concentrations are in the sewing room. High concentrations are more likely to be associated with workroom factors. With the exception of work related persistent cough, total inhalable dust in the personal breathing zone is not related to lower respiratory symptoms. It is, however, an independent predictor of reduced $\mathrm{FEV}_{1}$. Other independent factors predicting a reduced $\mathrm{FEV}_{1}$ are cumulative smoking, male sex, Asian ethnicity, and work in areas other than the weaving shed. Thus, reduced $\mathrm{FEV}_{1}$ is predicted by smoking, and personal and environmental factors. A reduced FVC is predicted by the same factors (except cumulative smoking).

We thank the Cotton Industry War Memorial Trust for their financial support which made this study possible.

1 Cited by Harris RT, et al. Byssinosis and respiratory diseases of cotton mill workers. F Occup Med 1974;14:199-206.

2 Mareska K, Heyman J. Enquete sur le travail et la condition et physique et morale des ouvries employes dans les manufacturers de cotton, a Gand. Ann Soc Med Gand 1845;16:5. Translation cited by Bouhuys A. Lung 1976;154:3-16.

3 Kay JP. Observations and experiments concerning molecular irritation of lungs as one source of tubercular lar irritation of lungs as one source of tubercular consumption; and on spinner's pthisis.

4 Arlidge JT. The hygiene diseases and mortality of occupations. London: Percival, 1892.
5 Collis EL. Factories and workshops: annual report for 1908 London: HMSO, 1908.

6 Prausnitz C. Investigation on respiratory dust disease in operatives in the cotton industry. Privy council, Medical Research Council. London: HMSO, 1936. (Special report series No 212.)

7 Schilling RSF, Hughes JPW, Dingwal-Fordyce I, et al. An epidemiological study of byssinosis among Lancashire cotton workers. Br F Ind Med 1955;12:217-26.

8 McKerrow CB, McDermott M, Gilson JC, et al. Respiratory function during the day in cotton workers: a study in byssinosis. Br F Ind Med 1958;15:75-83.

9 Mekky S, Roach SA, Schilling RSF. Byssinosis among winders in the cotton industry. Br f Ind Med 1967;24:123-32.

10 Fox AJ, Tombleson JBL, Watt A, et al. A survey of respiratory disease in cotton operatives. Part 1 . Symptom and ventilation test results. $\mathrm{Br} \mathcal{F}$ Ind $\mathrm{Med}$ 1973;30:42-7.

11 Fox AJ, Tombleson JBL, Watt A, et al. A survey of respiratory disease in cotton operatives. Part 2. Symptoms, dust estimation and the effect of smoking habit. $\mathrm{Br} \mathcal{F}$ Ind Med 1973;30:48-53.

12 Cinkotai FF, Rigby A, Pickering CAC, et al. Recent trends in the prevalence of byssinotic symptoms in the Lancashire textile industry. Br F Ind Med 1988;45:782-9.

13 Cinkotai FF, Seaborn D, Pickering CAC, et al. Airborne dust in the personal breathing zone and the prevalence of byssinotic symptoms in the Lancashire textile industry. byssinotic symptoms in the Lanca
Ann Occup Hyg 1988;32:103-13.

14 Berry G, Mckerrow CB, Molyneux MKB, et al. A study of acute and chronic change in ventilatory capacity of workers in Lancashire cotton mills. Br F Ind Med 1973;30:25-36.

15 Imbus H, Suh MW. Byssinosis: a study of 10133 textile workers. Arch Environ Health 1973;26:183-91.

16 Zuskin E, Valic F, Butkovic D, et al. Lung function in textile workers. Br F Ind Med 1979;32:283-8.

17 Beck GJ, Schacter EN, Maunder LR. The relationship of respiratory symptoms and lung function loss in cotton textile workers. Am Rev Respir Dis 1984;43:580-6.

18 Fishwick D, Fletcher AM, Pickering CAC, et al. Respiratory symptoms and dust exposure in Lancashire cotton and manmade mill operatives. Am $\mathcal{7}$ Respir Crit Care Med 1994; 150:441-7.

19 Field GB, Owen P. Respiratory function in an Australian cotton mill. Bulletin European de Physiopathologie Respiratoire 1979;15:455-68

20 Schacter EN, Kapp MC, Maunder LR, et al. Smoking and cotton dust effects in cotton textile workers: an analysis of the shape of the maximum expiratory flow volume curve. Environ Health Perspect 1986;66:145-8.

21 Schacter EN, Kapp MC, Beck, GJ, et al. Smoking and cotton dust effects in cotton textile workers. Chest 1989;95: 997-1003.

22 Roach SA, Schilling RSF. A clinical and environmental study of byssinosis in the Lancashire cotton industry. $\mathrm{Br} \mathcal{F}$ Ind Med 1960:17:1-9.

23 Merchant JA, Lumsden JC, Kilburn KH, et al. Dose response studies in cotton textile workers. F Occup Med 1973;15:222-30

24 Niven R Mcl, Fishwick D, Pickering CAC, et al. A comparison of two dust sampling techniques. Proceedings of the 15th Beltwide Cotton Dust Research Conference, 1991. Memphis, TN: National Cotton Council, 1991.

25 Corn M. Methods to assess airborne concentration of cotton dust. Am F Ind Med 1987;12:677-86.

26 Bouhuys A. Byssinosis in a cotton weaving mill. Arch Environ Health 1963;6:465-8.

27 Shivapuri HN, Varma MS. Byssinosis. F Indian Med Assoc 1957;29:322-4.

28 Schrag PE, Gullett AD. Byssinosis in cotton textile mills. Am Rev Respir Dis 1970;101:497-503.

29 Gupta S, Gupta BK. A study of byssinosis and associated respiratoy disorders in cotton mill workers. Indian $\mathcal{F}$ Chest Dis Allied Sci 1986;28:183-8.

30 Committee on Research into Chronic Bronchitis. Questionnaire on respiratory symptoms. London: Medical Research Council, 1966.

31 Quanjer PhH, Tammeling GJ, Cotes JE, et al. Lung volumes and forced expiratory flows. Report of the working party. Standardization of lung function tests. Official statement of the European Respiratory Society. Eur Respir $\mathcal{F}$ 1993; 6(suppl 16):5-40.

32 Merchant JA, Halprin G, Hudson AR, et al. Responses to cotton dust. Arch Environ Health 1975;30:222-9.

33 McDonald JB, Cole TJ. The flow volume loop: reproducibility of air and helium-based tests in normal subjects. Thorax 1980;35:64-9.

34 Quanjer PhH, Dalhuijsen A, Van Zomeron BC. Summary equations of reference values. Bulletin European de Physiopathologie Respiratoire 1983;19(suppl 5):45-51.

35 Cotes JE. Lung function, assessment and application in medicine, 4th ed. Oxford: Blackwell, 1979:349.

36 Mark D, Vincent JH. A new personal sampler for airborne total dust in workplace. Ann Occup Hyg 1986;30:89-102.

37 Vaughan NP, Milligan BD, Ogden TL. Filter weighing reproducibility and the gravimetric detection limit. Ann Occup Hyg 1989;33:331-7.

38 American Thoracic Society, statement. Snowbird workshop on standardisation of spirometry. Am Rev Respir Dis 1979; 119:831-8.

39 Walford J, Lammers B, Schilling RSF, et al. Diurnal variation in ventilatory capacity: an epidemiological study work. Br f Ind Med 1966;23:142-8. 
40 Kamat SF, Kamat GR, Salpekar VY, et al. Distinguishing byssinosis from chronic obstructive pulmonary disease; results of a prospective five year study of cotton
ers in India. Am Rev Respir Dis 1991;124:31-40.

41 Elwood PC, Sweetnam PM, Bevan C, al. Respiratory disability in ex-cotton workers. Br f Ind Med 1986;43:580-6.
42 Niven R Mcl, Fletcher AM, Pickering CAC, et al. Chronic bronchitis in textile workers. Thorax 1997;52: Chronic

43 Glind

Glindmeyer HW, Lefante RN, Jones RN, et al. Exposurerelated declines in the lung function of cotton textile workers. Am Rev Respir Dis 1991;144:675-83.

\section{Vancouver style}

All manuscripts submitted to Occup Environ Med should conform to the uniform requirements for manuscripts submitted to biomedical journals (known as the Vancouver style.)

Occup Environ Med, together with many other international biomedical journals, has agreed to accept articles prepared in accordance with the Vancouver style. The style (described in full in the $\mathcal{F} A M A[1]$ ) is intended to standardise requirements for authors, and is the same as in this issue.

References should be numbered consecutively in the order in which they are first mentioned in the text by Arabic numerals on the line in square brackets on each occasion the reference is cited (Manson[1] confirmed other reports[2][3][4][5]). In future references to papers submitted to Occup Environ Med should include: the names of all authors if there are three or less or, if there are more, the first three followed by et al; the title of journal articles or book chapters; the titles of journals abbreviated according to the style of Index Medicus; and the first and final page numbers of the article or chapter. Titles not in Index Medicus should be given in full.

Examples of common forms of references are:

1 International Committee of Medical Journal Editors. Uniform requirements for manuscripts submitted to biomed journals. FAMA 1993;269:2282-6.

2 Soter NA, Wasserman SI, Austen KF. Cold urticaria: release into the circulation of histmaine and eosinophil chemotactic factor of anaphylaxis during cold challenge. N Engl f Med 1976;294:687-90.

3 Weinstein L, Swartz MN. Pathogenic properties of invading micro-organisms. In: Sodeman WA Jr, Sodeman WA, eds. Pathologic physiology, mechanisms of disease. Philadelphia: W B Saunders, 1974:457-72. 